\title{
Numerical Simulation of Mechanical Properties of Defect Grouting Sleeve
}

\author{
Changjun WANG ${ }^{\mathrm{a}}$, Shibo LIANG ${ }^{\mathrm{b}}$, Zhijian $\mathrm{ZHAO}^{\mathrm{b}}$, Xiaonan $\mathrm{XU}^{\mathrm{b}}$, Sen PANG ${ }^{\mathrm{a}}$ and \\ Hongguang $\mathrm{ZHU}^{\mathrm{b}, 1}$ \\ a Beijing Building Research Institute Co.Ltd of CSCEC, 100076, Beijing, China \\ ${ }^{\mathrm{b}}$ China University of Mining \& Technology, School of Mechanics and Civil
}

Engineering, 100083, Beijing, China

\begin{abstract}
This paper proposes to use the cohesive bilinear contact model that comes with ABAQUS to simulate the bond-slip between steel grouting material; Establish a grouting sleeve connecting steel bar specimen model to simulate the mechanical performance of the end defect specimen and the middle defect specimen under different anchorage lengths, through the stress cloud diagram,Analyze the force transmission mechanism, reveal the influence mechanism of the end defect and the middle defect on the mechanical properties of the grouting sleeve.
\end{abstract}

Keywords. Reinforced sleeve, grouting defect, mechanical performance, cohesive force element, ABAQUS.

\section{Introduction}

Prefabricated buildings are the top priority for the development of the civil engineering industry in the future. Compared with traditional construction, it has the advantages of short construction period, less energy consumption, and controllable quality. It conforms to the concept of green and sustainable development. It has been applied and promoted in China in recent years [1].Lead to void defects inside the sleeve, these problems greatly affect the mechanical properties of the grouting sleeve [2].

The grouting sleeve was invented by Alfred.A.Yee [3]. in North America and applied for the first time in the frame structure concrete column. After more than half a century of development, it has been promoted to many countries and regions in the world.Zheng Qinglin [4] et al. conducted a uniaxial tensile test of 70 semi-grouting sleeves to analyze the influence of different grouting defects on the mechanical properties.Analyzing the test results, it is found that the end defect has little effect on the mechanical performance of the test piece compared with the horizontal defect and the middle defect;Li Xiangmin, Gao Rundong [5]conducted experiments on three grouting sleeves with different diameters and different anchoring lengths. The research results show that the middle defect has a greater impact on the mechanical properties of the grouting sleeve.In addition to the experiment, Zhao Jun [6] used ANSYS software to build a grouting sleeve model, and analyzed the stress distribution of the steel-grouting and grouting-sleeve contact surfaces. The results show that the shear key of the steel rib

${ }^{1}$ Corresponding Author, Hongguang ZHU, China University of Mining \& Technology, School of Mechanics and Civil Engineering, 100083, No. 11, Xueyuan Road, Haidian District, Beijing, China; Email: Zhg@cumtb.edu.cn. 
and the sleeve is the key part of the sleeve bearing capacity;Wang Rui [7] et al. used ABAQUS finite element software to compare and verify with the experiment, and the results are more consistent. $\mathrm{Wu}$ Tao [8] et al. Conducted a uniaxial tensile test of a grouting sleeve, analyzed the influence of sleeve type, steel bar diameter and anchoring length on the strain of the sleeve wall, and performed simulation verification with ANSYS finite element software.

\section{Establishment of Finite Element Model}

A finite element model was established based on the specimen size and material parameters of the sleeve tested by Kuang Zhiping [9].

\subsection{Model Parameters}

(1)Sleeve geometry

The structure of GT420 type sleeve is shown in the figure 1, and the structure size of the grouting sleeve is shown in relevant specifications.

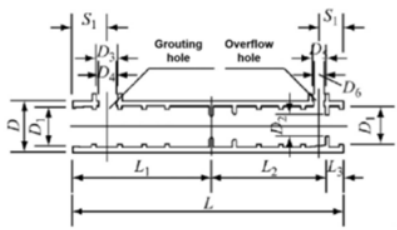

Figure 1. Schematic diagram of

Figure 2. Schematic diagram of modeling of

longitudinal section of full grouting sleeve

grouting sleeve connecting steel bar specimens

(2) Rebar size

The length of the reinforcement on the grouting side is $300 \mathrm{~mm}$, and the length of the reinforcement on the overflow side is $310 \mathrm{~mm}$, The diameter of the steel bar is $20 \mathrm{~mm}$. The anchorage length of the grouting side steel bar is $160 \mathrm{~mm}$, which is $8 \mathrm{~d}$; the anchoring length of the overflow side steel bar is $170 \mathrm{~mm}$, which is $8.5 \mathrm{~d}$, and $\mathrm{d}$ is the diameter of the steel bar [10].

(3) ABAQUS modeling processing

In view of the main analysis problems, in order to improve work efficiency, this chapter makes the following simplified treatments when establishing the numerical model of the grouting sleeve connecting steel bar specimens:

1.Do not draw crescent ribs when modeling steel bars;

2.The interior of the grouting sleeve is simplified as a smooth cylinder;

3.The grouting sleeve connecting steel bar specimen is equivalent to an axisymmetric model. As shown in figure 2.

\subsection{Material Model}

\section{(1)Grouting}

Grouting is a dry mixture, which uses cement as the basic material, mixed with a certain composition of fine aggregates, concrete admixtures and other materials. When in use, the grouting material is mixed with water to form a cement-like sticky body, which has 
good fluidity, early strength, high strength, and micro-expansion properties, and has certain similarities with concrete.Therefore, the concrete CDP model is adopted. At the same time, this paper simulates the expansion of the grout by using the thermal simulation method.The thermal expansion coefficient characterizes the thermal expansion and contraction characteristics of the matrix. It is assumed to be isotropic expansion, and the expansion coefficient is the same in the three spatial directions. In this paper, the coefficient of thermal expansion is set to 0.0006 .

The following table 1 shows the strength of the grouting material used in the literature. It can be seen that the strength of the grouting material is $82.78 \mathrm{MPa}$, so the $\mathrm{C} 80$ concrete CDP model is used in the model.

Table 1. Statistical results of grouting compressive strength test

\begin{tabular}{|c|c|c|}
\hline Age/d & Specimen number & Average intensity $\mathbf{f}_{\mathbf{c}} / \mathbf{M P a}$ \\
\hline 1 & $\mathrm{C}-01$ & 39.29 \\
\hline 3 & $\mathrm{C}-02$ & 65.53 \\
\hline 28 & $\mathrm{C}-03$ & 82.88 \\
\hline
\end{tabular}

The grouting material uses a concrete plastic damage model, which is mainly used to simulate the mechanical performance of concrete structures under cyclic and dynamic loads. The expansion angle is $30^{\circ}$; the eccentricity is $0.1 ; 1.16 ; \mathrm{K}$ is 0.66667 ; the viscosity parameter is 0.005 .

(2)Rebar

The steel bar adopts the ideal elastoplastic three-fold line model, and its parameters are derived from the yield strength, ultimate strength, yield platform length and ultimate strain of the test control group. Since the test control group has three groups, the parameters are averaged. The Poisson's ratio is 0.3 . The parameters are as follows table 2:

Table 2. Performance test results of reinforcing steel materials

\begin{tabular}{|c|c|c|c|c|}
\hline $\begin{array}{c}\text { Specimen } \\
\text { number }\end{array}$ & $\mathbf{b - 1}$ & $\mathbf{b - 2}$ & $\mathbf{b - 3}$ & average value \\
\hline $\begin{array}{c}\text { Yield Strength } \\
f_{\text {ym }} / \mathrm{MPa}\end{array}$ & 440.76 & 439.88 & 441.81 & 440.82 \\
\hline $\begin{array}{c}\text { Ultimate strength } \\
f_{y m} / \mathrm{MPa}\end{array}$ & 616.70 & 614.83 & 614.57 & 615.37 \\
\hline $\begin{array}{c}\text { Yield platform } \\
\text { length } \Delta \varepsilon_{y m}(\times \\
\left.10^{-3}\right)\end{array}$ & 17.7 & 18.3 & 17.9 & 17.97 \\
\hline Ultimate strain $\varepsilon_{u m}$ & 0.302 & 0.285 & 0.327 & 0.305 \\
\hline
\end{tabular}

(3)Sleeve

The test results show that the sleeve is always in an elastic state, so the sleeve material adopts an ideal elastic model. The elastic modulus is $2 \times 105 \mathrm{MPa}$, and the Poisson's ratio is 0.3 .

\subsection{Contact and Boundary Conditions}

When the grouting sleeve is subjected to unidirectional tensile load, two failure modes occur in the connecting steel bars of the grouting sleeve, namely, steel bar breakage failure and steel pull-out failure. Therefore, the model uses ABAQUS's own cohesive 
bilinear contact model between the steel bar and the grouting material. The parameters are taken from the bond-slip constitutive between the steel bar and the grouting material previously studied, and the maximum nominal stress criterion is used for damage. In the contact properties, set the friction coefficient, the friction coefficient is set to 0.5 , and set the "hard" contact in the normal behavior.

\section{Numerical Simulation Results and Analysis}

\subsection{Influence of End Defects on the Mechanical Performance of Grouting Sleeve}

When the grouting sleeve connecting steel bar specimens with end defects are subjected to uniaxial tensile load, high stress repeated tension and compression, and large deformation repeated tension and compression, when the anchoring length of the reinforcement on the overflow side changes,

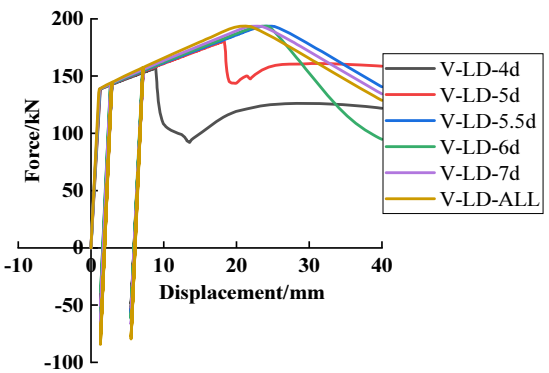

(a)

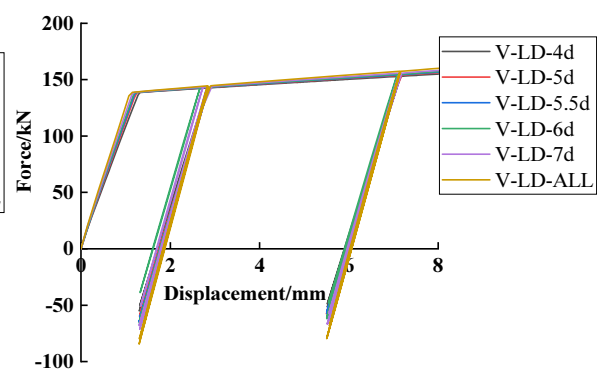

(b)

Figure 3. Large deformation and repeated tension and compression contain end defects

Under the action of large deformation and repeated tension and compression of the grouting sleeve connecting steel bar specimens, the anchorage lengths of the end defects of the steel bars on the overflow side are respectively $4 \mathrm{~d}, 5 \mathrm{~d}, 5.5 \mathrm{~d}, 6 \mathrm{~d}, 7 \mathrm{~d}$, and when fully filled, The load-displacement curve of the numerical simulation is shown in figure 3 . It can be seen from figure 3(a) that for the end defect, when the anchorage length of the steel bar is $4 \mathrm{~d}$ and $5 \mathrm{~d}$, the steel bar specimens connected by the grouting sleeve will fail after the steel bar yields. When the anchorage length of the steel bar on the overflow side is greater than $5.5 \mathrm{~d}$, the steel bar specimens connected by the grouting sleeve all suffered steel bar breakage.

Figure 3(b) shows the load-displacement curve of the large deformation repeated tension-compression cyclic loading under different anchorage lengths of the end defect of the overflow side steel bar. It can be seen from the figure that the curve of the rising section of the first forward load is the same as that of the uniaxial tensile load. When the load reaches the first-level control displacement level, the curve has entered the yield section and even strengthened;The first positive unloading is also due to the elastic shrinkage of the steel bars, and the deformation is partially restored. However, due to the friction resistance between the steel bars and the grouting material, the amount of deformation recovery is not large, and the steel bars have undergone obvious plastic deformation. 


\subsection{Influence of Defects in the Middle on the Mechanical Performance of Grouting Sleeve}

The analysis results are as follows when the anchorage length of the reinforcement on the overflow side changes under the action of three different loads on the grouting sleeve connecting steel bar specimen containing the middle defect:
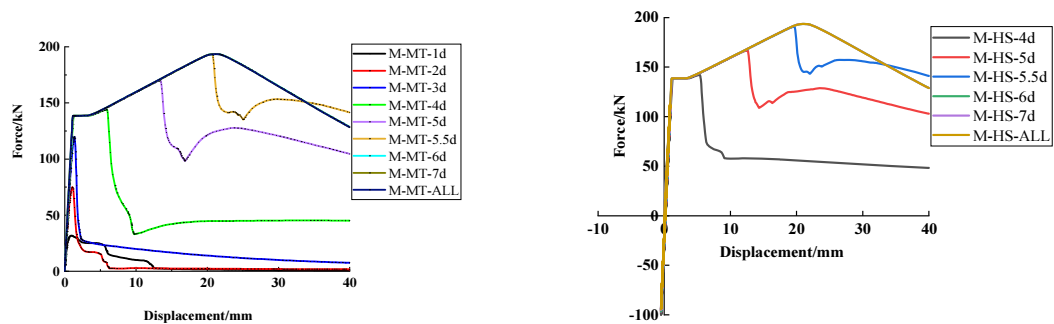

Figure 4. Uniaxial stretching

Figure 5. High-stress repeated tension and central defect force compression containing central defect force-displacement curve

It can be seen from figure 4 that for the middle defect, when the anchoring length of the reinforcement on the overflow side is $1 \mathrm{~d} \sim 3 \mathrm{~d}$, the grouting sleeve connected steel bar specimens will be pulled out before the steel bar yields. When the anchoring length of the steel bar on the overflow side is $4 \mathrm{~d}, 5 \mathrm{~d}, 5.5 \mathrm{~d}$, the steel bar specimens connected by the grouting sleeve will be pulled out after yielding. When the anchorage length of the reinforcement on the overflow side is greater than $6 \mathrm{~d}$, the reinforcement specimens connected by the grouting sleeve all have the reinforcement failure.

It can be seen from figure 5 that for the middle defect, when the anchoring length of the reinforcement on the overflow side is $4 \mathrm{~d}, 5 \mathrm{~d}, 5.5 \mathrm{~d}$, the grouting sleeve connected steel bar specimens will fail after the steel bar yields. When the anchorage length of the reinforcement on the overflow side is greater than $6 \mathrm{~d}$, the reinforcement specimens connected by the grouting sleeve all have the reinforcement failure.

\section{Analysis of Stress Field of Steel Bar Specimens Connected By Grouting sleeve}

\subsection{End Grouting Defect}

For the grouting-sleeve-connected steel bar specimens containing grouting end defects, the stress transfer mechanism and change law of the steel bar, grouting and grouting sleeves are almost the same as the situation when they are full. The differences are:

(1)The stress at the defective end of the grouting material is greater than the stress at the full end, as shown in figure 6(a). This is due to the reduction of the anchorage length of the steel bars, which leads to a reduction in the contact area between the steel bars on the overflow side and the grouting material, so that under the same force, the stress at the defective end of the grouting material is greater than the stress at the full end.

(2)For the sleeve that does not bond with the grout, this part is almost free of force, as shown in figure 6(b). This is because this part is not in contact with the grouting material, so it cannot withstand the tensile force of the steel bars transmitted through the grouting material. 


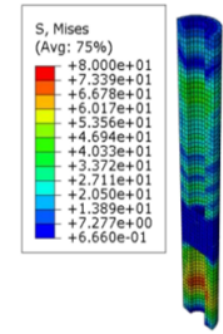

(a)

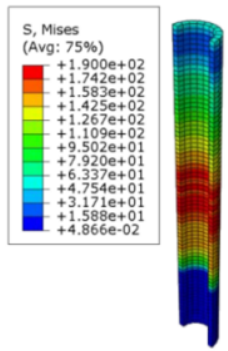

(b)

Figure 6. Stress cloud diagram of grouting and grouting sleeve before V-MT-4d steel bar is pulled out

From the above stress cloud diagram, it can be seen that due to the end defect, under the same load, the force of the grouting material at the defect end is more concentrated, which will increase the deformation of the grouting material.This affects the bonding performance between the steel bar grouting material, and then weakens the bonding strength of the steel bar grouting material. Therefore, when the end defect increases to a certain extent, the bond strength between the steel bar and the grouting material is less than the tensile strength of the steel bar, and the steel bar pull-out failure occurs.

\subsection{Contains a Central Defect}

For the grouting sleeve connecting steel bar specimens containing grouting central defects, the stress transfer mechanism and change law of the steel bar, grout and grouting sleeve are basically the same as the situation when it is full. The differences are:

(1)When there is a hollow defect in the middle and the steel bar breaks, the stress of the grouting defect end is greater than the stress of the non-defect end, and for the stress of the defect end, the stress of the grouting inside the sleeve is greater than the stress of the grouting near the overflow port. , As shown in figure 7(a).

(2)When the test piece is pulled out and damaged, the stress at the end of the grouting containing the defect in the middle will be transferred from the inner end of the sleeve to the end close to the overflow port, as shown in figure $7(\mathrm{~b}) \sim(\mathrm{c})$.

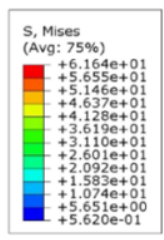

(a)
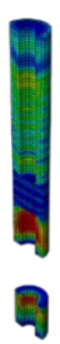

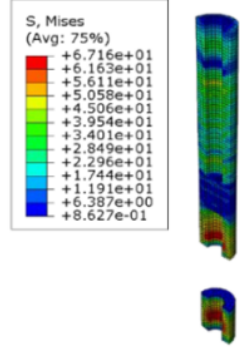

(b)

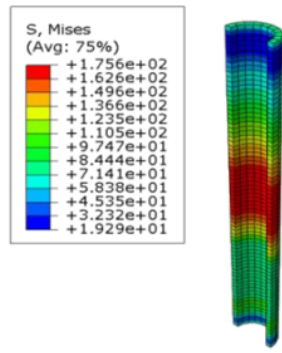

(c)

Figure 7. H-MT-5d (pulling out failure) stress cloud diagram of grouting material and grouting sleeve at different moments

It can be seen from the above stress cloud diagram that when the size of the defect is the same, the middle defect is located in the middle of the grouting material, so that under the same force, there will be grouting material on both sides of the middle defect of the grouting material.Therefore, the central defect has a greater adverse effect on the grouting sleeve connecting steel bar specimens. 


\section{In Conclusion}

The stress cloud diagram in the grouting sleeve connecting steel bar specimen is explained, and the force transmission mechanism of the contact surface, the stress distribution law and the force condition of each part are analyzed.The influence mechanism of the end defect and the middle defect on the mechanical properties of the grouting sleeve is revealed. The research results show that:

(1)To ensure that the steel bars connected by the full grouting sleeve will break and fail, the anchorage length of the rebar at the middle defect shall not be less than $6 \mathrm{~d}$, and the anchorage length of the rebar at the end defect shall not be less than $5.5 \mathrm{~d}$.

(2)In the grouting sleeve connecting steel bar test piece, the main stress parts of the steel bar are located at the two ends of the outer side of the sleeve mouth; The force of the grouting material is relatively uniform, the stress on the contact surface of the steel bar and the grouting material is greater than the stress in other areas, there is no contact with the steel bar, and the grouting material in the middle part has the least stress and is basically free of force; The main force-bearing part of the sleeve is located in the middle part of the sleeve, that is, the middle part is large and the two ends are small. In this regard, the author proposes an optimization scheme for the grouting sleeve, which can be partially strengthened in the middle part of the grouting sleeve, and the thickness of the two ends of the sleeve can be reduced.

(3)Due to the grouting defect, under the same load, the force of the grouting at the defect end is more concentrated.This will increase the deformation of the grouting material, thereby affecting the bonding performance between the steel bar grouting material, and thereby weakening the bonding strength of the steel bar grouting material. Therefore, when the end defect increases to a certain extent, the bond strength between the steel bar and the grouting material is less than the tensile strength of the steel bar, and the steel bar pull-out failure occurs. The defects in the middle part make the grouting material inconsistent and the force of the grouting material is more concentrated. Therefore, the middle part defects have a greater adverse effect on the grouting sleeve connecting steel bar specimens.

\section{Acknowledgments}

This paper is supported by the scientific research project of China Construction Corporation (CSCEC-2019-Z-4). I would like to express my gratitude.

\section{References}

[1] Guo Xueming. Structure and design of prefabricated concrete buildings [M]. Beijing: Machinery Industry Press, 2018

[2] Gao Rundong, Li Xiangmin, Xu Qingfeng. Problems and solutions of sleeve grouting in assembled integral concrete buildings Omitted [J]. Construction technology, 2018, 47 (10): 1-4,10

[3] Yee A.A. New precast prestressed system saves money in Hawaii hotel[J]. PCIJournal. 1973, 18( 3):10-13.

[4] Zheng Qinglin, Wang Ni, Tao Li, et al. Test on the effect of grouting defects on the properties of reinforced sleeve grouting connection specimensResearch [J]. Building science, 2017,33 (05): 61-68

[5] Gao Rundong, Li Xiangmin, Xu Qingfeng. Problems and solutions of sleeve grouting in assembled integral concrete buildingsOmitted [J]. Construction technology, 2018, 47 (10): 1-4,10

[6] [Zhao Jun, Du Yanbing, Zhu wanxu, Zhang Minghao. Finite element analysis of grouting sleeve connecting members [J]. Concrete, 2019 (10): 150-154 
[7] Wang Rui, Chen Jianwei, Wang Ning. Finite element analysis of reinforced sleeve grouting connection performance [J]. Journal of North China University of Technology (NATURAL SCIENCE EDITION), 2019,41 (01): 47-56

[8] Wu Tao, Wang Zhen, Liu Yibin, Zhang Bin. Mechanical properties of reinforced sleeve grouting connectors [J]. Journal of building science and engineering, 2019,36 (02): 21-29

[9] Kuang Zhiping, Zheng Guanyu, Jiao Xuetao. Test on the influence of insufficient grouting on the mechanical properties of reinforced sleeve connection [J]. The same as Journal of Jinan University (NATURAL SCIENCE EDITION), 2019, 47 (07): 934-945

[10] Ministry of housing and urban rural development of the people's Republic of China. Sleeve grouting material for reinforcement connection [S]. Beijing. 2013 